\title{
Editorial
}

\section{Biochemia Medica appoints Research integrity editor}

\author{
Ana-Maria Simundic \\ Editor-in-chief, Biochemia Medica, Zagreb, Croatia \\ Corresponding author:am.simundic@gmail.com
}

\begin{abstract}
Biochemia Medica has just established the Research integrity editor who will act as the Editorial team member responsible for all matters related to the various aspects of scientific misconduct. The major reason for this is the increasing number of various types of scientific misconduct in manuscripts submitted to our Journal. Research integrity editor will: a) strive to continuously raise awareness for research and publication integrity issues; $b$ ) educate our authors, reviewers and readers, by providing educational articles on various topics related to responsible research and writing; $c$ ) aim to prevent unethical research and publication practices; and d) responsibly deal with research and publication misconduct attempts in accordance with internationally accepted policies and recommendations. This initiative provides firm evidence of our commitment and respect for publishing ethical and responsible research. By this we hope to further increase the scientific quality of the journal content as well as the quality of the editorial work.
\end{abstract}

Key words: scientific misconduct; plagiarism; editorial policies

Accepted: July 15, 2012

We wish to announce that Biochemia Medica has established the position of Research integrity editor. Research integrity editor is a member of the Editorial team of Biochemia Medica whose responsibility will be to deal with all matters related to the various aspects of scientific misconduct and act as a gatekeeper of responsible scientific and publication policies (1).

The reason for this initiative is an ever increasing frequency of various types of scientific misconduct in manuscripts submitted to our Journal. With this new editor on Board we hope to be able to:

- raise awareness for research and publication integrity issues,

- educate our authors, reviewers and readers,

- prevent unethical research and publication practices,

\section{References:}

1. Marusic A. Editors as gatekeepers of responsible science. Biochem Med 2010;20:282-7.

2. Simundic AM. Editing a scientific journal in Croatia: the case of Biochemia Medica. Eur Sci Edit 2012;38:69
- deal with research and publication misconduct attempts in accordance with internationally accepted policies and recommendations.

Editors at Biochemia Medica hope that this initiative shows how much we appreciate and respect ethical and responsible research (2). We strongly encourage our readers and reviewers as well as other journal editors to report each and every potential scientific misconduct in manuscripts either submitted or published in our Journal. To effectively deal with plagiarism attempts, we will also soon start routinely screening every submission to our Journal with plagiarism detection software (3). We see this important step as a part of our continuous improvement efforts, aimed to increase the scientific quality of the content of our journal as well as the quality of the editorial work.

3. Baždarić K, Bilić-Zulle L, Brumini G, Petrovečki M. Prevalence of plagiarism in recent submissions to the Croatian Medical Journal. Sci Eng Ethics 2012;18:223-39 